\title{
BMJ Open Direct inpatient costs and influencing factors for patients with rectal cancer with low anterior resection: a retrospective observational study at a three-tertiary hospital in Beijing, China
}

\author{
Zhishui Chen, ${ }^{1}$ Jiahua Leng, ${ }^{1,2}$ Guangying Gao, ${ }^{3}$ Lianhai Zhang, ${ }^{4}$ Yang Yang ${ }^{4}$
}

To cite: Chen Z, Leng J, Gao G, et al. Direct inpatient costs and influencing factors for patients with rectal cancer with low anterior resection: a retrospective observational study at a three-tertiary hospital in Beijing, China. BMJ Open 2018;8:e023116. doi:10.1136/ bmjopen-2018-023116

- Prepublication history for this paper is available online. To view these files, please visit the journal online (http://dx.doi org/10.1136/bmjopen-2018023116).

Received 24 March 2018 Revised 13 October 2018 Accepted 23 November 2018

A) Check for updates

(C) Author(s) (or their employer(s)) 2018. Re-use permitted under CC BY-NC. No commercial re-use. See rights and permissions. Published by BMJ.

For numbered affiliations see end of article.

Correspondence to

Dr Jiahua Leng;

lengybc@126.com

\section{ABSTRACT}

Objectives The aim of the study was to investigate the direct inpatient cost and analyse influencing factors for patients with rectal cancer with low anterior resection in Beijing, China.

Design A retrospective observational study.

Setting The study was conducted at a three-tertiary oncology institution.

Participants A total of 448 patients who underwent low anterior resection and were diagnosed with rectal cancer from January 2015 to December 2016 at Peking University Cancer Hospital were retrospectively identified. Demographic, clinical and cost data were determined.

Results The median inpatient cost was $¥ 89064$, with a wide range ( $¥ 46711-¥ 191329$ ) due to considerable differences in consumables. The material cost accounted for $52.19 \%$ and was the highest among all the cost components. Colostomy (OR 4.17; 95\% Cl 1.79 to 9.71), complications of hypertension (OR 5.30; $95 \% \mathrm{Cl} 1.94$ to 14.42 ) and combined with other tumours (OR 2.92; $95 \% \mathrm{Cl}$ 1.12 to 7.60 ) were risk factors for higher cost, while clinical pathway (OR $0.10 ; 95 \% \mathrm{Cl} 0.03$ to 0.35 ), real-time settlement (OR $0.26 ; 95 \% \mathrm{Cl} 0.10$ to 0.68 ) and combined with cardiovascular disease (OR $0.09 ; 95 \% \mathrm{Cl} 0.02$ to 0.52 ) were protective determinants.

Conclusions This approach is an effective way to relieve the economic burden of patients with cancer by promoting the clinical pathway, optimising the payment scheme and controlling the complication. Further research focused on the full-cost investigation in different stages of rectal cancer based on a longitudinal design is necessary.

\section{BACKGROUND}

Colorectal cancer (CRC) is the most common gastrointestinal malignancy. In China, the incidence rate of CRC ranks third in malignant tumours and is still in the rising stage, and the mortality rate ranks fifth. ${ }^{1-3}$ According to the overall death of cancers, colorectal neoplasm ranks second and accounts for $10.5 \%{ }^{4}$ Approximately $70 \%$ of CRC is rectal cancer, and approximately $70 \%$ of CRC occurs in the middle and low position. ${ }^{56}$ The treatment is
Strengths and limitations of this study

- This was a study with a large sample size designed for low anterior resection, so our findings are likely to be representative of patients in China.

- The analyses were based on existing data from hospital information systems. Demographic, diagnosis and treatment characteristics were precisely gathered.

- Forest plot is an efficient graphical display for presenting estimated effect sizes and their Cls; therefore, we applied forest plot to visualise the associations between the indicators and the direct medical costs

- We focused solely on direct medical costs and did not examine indirect costs; thus, full-cost investigation at the regional or national level should be considered in future research.

mainly based on surgery. ${ }^{78}$ There are many types of surgical approaches, and the sphincter-saving procedure is currently considered to be the mainstay of therapy, including low anterior resection (LAR), intersphincteric resection and transanal excision. LAR is widely applied to CRC..$^{910}$

LAR is principally carried out on the CRC above the peritoneal reflection. According to previous researchers, ${ }^{811} 12$ the local recurrence rate of patients after LAR was $7.14 \%$, the distant metastasis rate was $11.9 \%$ and the 3-year postoperative survival rate was $68.6 \%$. Compared with other surgeries, the outcome of LAR is more satisfactory. ${ }^{13}$ Previous studies focused primarily on the selection of surgical approaches, the extent of operation, prognosis and quality of life ${ }^{14-17}$ while studies addressing its economic burden are relatively lacking.

To address this gap, we conducted this study to analyse the direct hospitalisation 
expense and its cost structure for patients with rectal cancer receiving LAR within a representative Beijing oncology hospital. Furthermore, influencing factors of the hospitalisation cost that were measured by regression analysis and depicted by forest plot were identified. These results may contribute to a better understanding of the economic burden of rectal cancer in Beijing and help to pave the way for a healthcare payment system reform and its economic evaluation.

\section{MATERIALS AND METHODS \\ Study design and setting}

This is a retrospective study that does not involve ethical issues. The study was not designed as a clinical efficacy investigation for LAR; thus, no sample size calculation or non-inferiority test was conducted. All data were retrospectively collected from the hospital-based information system. Conducted at Peking University Cancer Hospital (PUCH), which received patients with CRC from all over the country, the study had enough cases for cost analysis.

\section{Study participants}

From January 2015 to December 2016, 1596 cases with a primary diagnosis of rectal cancer (International Classification of Diseases 10th revision: C20) were identified. The criteria for exclusion were as follows: (1) lacking detailed surgical records; (2) length of stay (LOS) less than 3 days or more than 24 days, which went beyond $90 \%$ CI of LOS; (3) without tumour, node, metastases stage and (4) non-LAR surgery. Finally, we obtained a total of 448 cases. Figure 1 shows the retrieval procedure.

\section{Patient and public involvement}

No patients or public were involved in this study. Nor were they involved in developing plans for the design or implementation of the study. There are no plans to disseminate the results of the research to study participants.

\section{Data collection}

According to the inclusion and exclusion criteria, we reviewed the medical records of those patients from the Hospital Electronic Patient Records System (HEPRS). The HEPRS entitled us to acquire the real-time query of patients' records. The main variables included demographic characteristics (age, gender and payment), diagnosis (complication, pathological type, differentiation and neoplasm stage), treatment (operation strategy, colostomy, clinical pathway, planned readmitted and specialty) and direct medical expenses. Although China has developed a mixed health insurance system, such as urban employees basic medical insurance, urban and rural residents basic medical insurance and supplementary catastrophic disease health insurance, patients pay for all medical expenses when they choose cross-regional medical care. Given the regional blocks, these patients need to return to their place of residence for reimbursement. Therefore, we divide the 'payment' into a cash

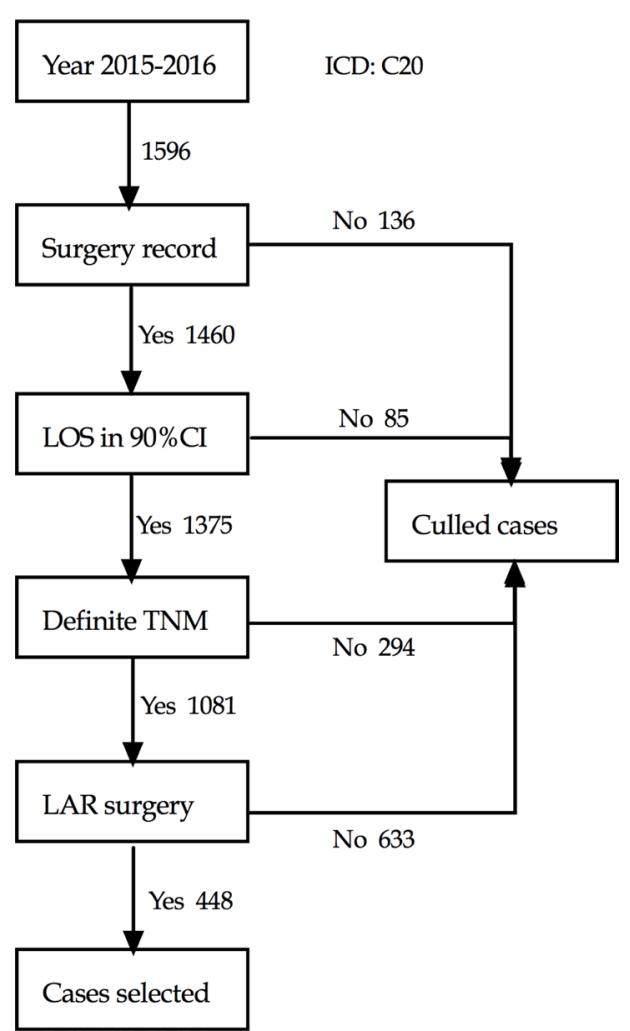

Figure 1 Retrieval procedure of LAR surgery for patients with rectal cancer in PUCH. After these steps, we excluded 1148 cases and identified 448 patients precisely. ICD, International Classification of Diseases; LAR, low anterior resection; LOS, length of stay; PUCH, Peking University Cancer Hospital; TNM, tumour, node, metastases.

payment group and a real-time settlement group. The former refers to patients who were reimbursed at their place of residence, and the latter refers to patients who were reimbursed in Beijing. We considered cardiovascular disease, hypertension, diabetes and other tumours (including colon, liver, ovarian, cervix and lung cancer) as 'complication'. The operation strategy was divided into open surgery and laparoscopic surgery. 'Clinical pathway' referred to whether the patient followed the standard digital clinical pathway provisions, and ' $\mathrm{Y}$ ' means a clearly defined protocol of care. 'Planned readmitted' referred to whether patients were hospitalised that had planned previously, and ' $\mathrm{Y}$ ' means elective surgery. 'Specialty in' referred to whether patients were treated in a professional and designated department, and ' $\mathrm{Y}$ ' means a specialist colorectal unit.

\section{Cost measurements}

The study only calculated the direct medical cost, that is, the total treatment cost in the process of inpatient service. According to HEPRS, direct hospitalisation cost can be accumulated into four categories: drug cost, material cost, examination and treatment cost and other costs. In 2016, the Consumer Price Index of Beijing was 101.4, and we think of 1.014 as the discount rate. Additionally, inpatient cost was statistically divided into four grades by means of quartiles $(0 \%-25 \%, 25 \%-50 \%$, 
$50 \%-75 \%$ and $75 \%-100 \%)$, that is, costs were divided into below $¥ 73281$ (group 1 ), $¥ 73$ 281- $¥ 89065$ (group 2 ), $¥ 89$ 065- $¥ 106438$ (group 3) and above $¥ 106438$ (group 4) sequentially. Cost data were not normally distributed, so we used the median and IQR to describe the cost situation.

\section{Statistical analysis}

SPSS V.22.0.0.0 software was used for data analysis and all statistics. The median and IQR of costs were calculated in our study. Pearson $\chi^{2}$ or Fisher's exact test was performed to compare the differences within inpatient characteristics. The influencing factors were analysed by ordinal logistic regression, and the ORs were illustrated by forest plot. All statistical approaches were applied assuming a two-sided test based on a 5\% level of type I error. $\mathrm{P}<0.05$ was considered to be statistically significant.

\section{RESULTS}

\section{General characteristics}

A total of 448 hospital clinical files were collected. The age group of 51-60 accounted for 33.5\% of all patients. Males accounted for $63.6 \%$. In stage III, $39.3 \%$ were moderately differentiated, and $83.7 \%$ were moderately differentiated. A total of 334 cases belonged to the realtime settlement, accounting for $74.6 \%$. A total of $57.8 \%$ were given consent to the colostomy. Additionally, $32.1 \%$ were combined with other neoplasms. A total of 30, 114, 57 cases had complications with cardiovascular disease, hypertension or diabetes. Approximately $7.1 \%$, 81.2\% and $94.2 \%$ of patients received laparoscopic surgery, clinical pathway or specialty treatment, respectively. The data compilations are shown in table 1.

\section{Direct medical costs}

The direct medical cost for LAR inpatients ranged from $¥ 46711$ to $¥ 191329$, with a median cost of $¥ 89064$. The cost distribution histogram is shown in figure 2 , in which the medical cost between $¥ 76000$ and $¥ 100000$ occupied the maximum proportion. The cost structure is shown in table 2 . The results showed that material cost accounted for $52.19 \%$ and drug cost accounted for $30.75 \%$.

\section{Univariate analysis}

A total of 448 cases were divided into four cost categories according to the cost volume. Table 3 shows that cost group 4 accounted for $31.9 \%$ in the age group of $>70$ years, and $31.7 \%$ of patients were in cost group 1 in the non-colostomy group. In cost group 4, stage IV accounted for 45.8\%. According to the univariate analysis, there were no significant differences between age, gender, payment, operation strategy, planned readmitting and differentiation with cost group $(p>0.05)$. Nevertheless, differences between complications

\begin{tabular}{|c|c|c|c|c|c|}
\hline Variables & No cases & $\%$ & Variables & No cases & $\%$ \\
\hline Age & & & Clinical pathway & & \\
\hline$<50$ & 86 & 19.2 & $\mathrm{Y}$ & 364 & 81.2 \\
\hline $51-60$ & 150 & 33.5 & N & 84 & 18.8 \\
\hline $61-70$ & 143 & 31.9 & Planned readmitted & & \\
\hline$>70$ & 69 & 15.4 & Y & 74 & 16.5 \\
\hline Gender & & & $\mathrm{N}$ & 374 & 83.5 \\
\hline Female & 163 & 36.4 & Specialty in & & \\
\hline Male & 285 & 63.6 & Y & 422 & 94.2 \\
\hline Payment & & & N & 26 & 5.8 \\
\hline Cash payment & 334 & 74.6 & Pathological type & & \\
\hline Real-time settlement & 114 & 25.4 & Adenocarcinoma & 420 & 93.8 \\
\hline Complications & & & Others & 28 & 6.3 \\
\hline Other tumours & 144 & 32.1 & Differentiation & & \\
\hline Cardiovascular disease & 30 & 6.7 & Undetermined & 24 & 5.4 \\
\hline Hypertension & 114 & 25.4 & Poorly differentiated & 45 & 10.0 \\
\hline Diabetes & 57 & 12.7 & Moderately differentiated & 375 & 83.7 \\
\hline Operation strategy & & & Well differentiated & 4 & 0.9 \\
\hline Open surgery & 416 & 92.9 & Neoplasm stage & & \\
\hline Laparoscopic surgery & 32 & 7.1 & I & 90 & 20.1 \\
\hline Colostomy & & & II & 158 & 35.3 \\
\hline$Y$ & 259 & 57.8 & III & 176 & 39.3 \\
\hline $\mathrm{N}$ & 189 & 42.2 & IV & 24 & 5.3 \\
\hline
\end{tabular}




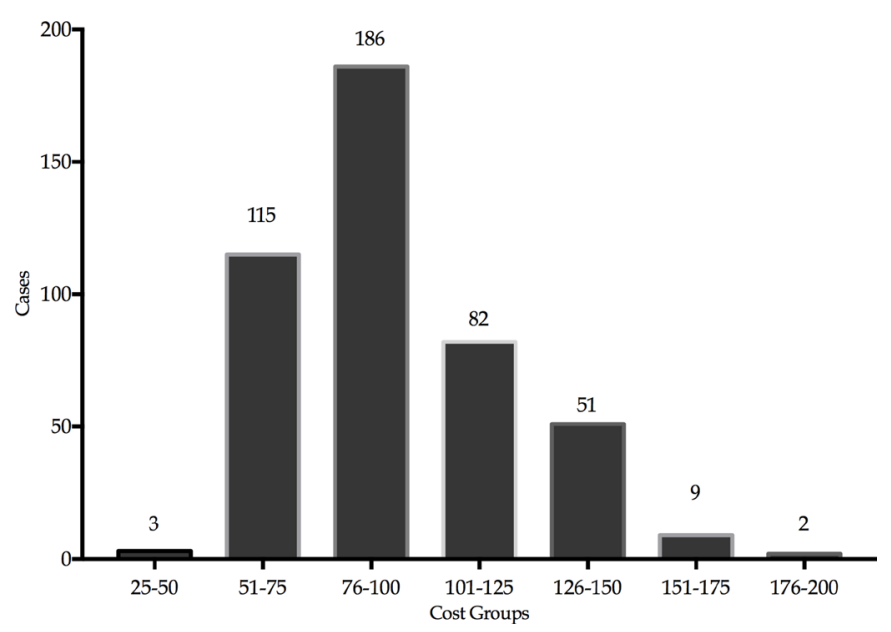

Figure 2 Cost distribution histogram for low anterior resection surgical inpatients (unit: $¥ 1000$ ). The interval of grouping was set to $¥ 25000$, and thus all cases were categorised into seven groups.

of hypertension, colostomy, clinical pathway and neoplasm stage with cost group were recognised $(p<0.05)$.

\section{Multivariate analysis}

Based on the results of the univariate analysis, the identification of influencing factors that affected the cost group was analysed by ordinal logistic regression. The $\mathrm{X}^{2}$ goodness-of-fit test of the model was 70.913, and the $\mathrm{p}$ value was 0.000; thus, the model was effective. The results of the ORs of multivariate regression are shown in figure 3 . The figure revealed that combined cardiovascular disease, clinical pathway and real-time settlement were protective factors for inpatient cost. Meanwhile, colostomy, combined with other tumours and hypertension were risk factors. Numerically, the risk of incremental inpatient costs for colostomy was 4.17 times higher than that of non-colostomy patients, and the risk of hypertension was 5.30 times larger than that of non-hypertension.

\section{DISCUSSION}

This study analysed the direct medical cost of LAR surgery for patients with rectal cancer over the past 2years in the Beijing healthcare setting. There was a wide range in costs ( $¥ 46711-¥ 191329$ ) among those selected patients, mainly

Table 2 The cost structure for low anterior resection surgical inpatients (unit: $¥ 1$ )

\begin{tabular}{lrrl}
\hline Cost structure & Median & IQR $^{*}$ & \% \\
\hline Drug cost & 24583 & 17386 & 30.75 \\
Material cost & 48657 & 17564 & 52.19 \\
$\begin{array}{l}\text { Examination and } \\
\text { treatment cost }\end{array}$ & 13627 & 4478 & 15.52 \\
Other cost & 1110 & 660 & 1.54 \\
Total cost & 89064 & 33157 & 100 \\
\hline
\end{tabular}

${ }^{*} \mathrm{IQR}$ referred to the IQR statistically. The reason for using median and IQR was because of its abnormal distribution. because of the discrepant drugs and disposable medical materials for surgery, which accounted for upwards of $80 \%$ of the total direct cost. Similarly, Mohd-Dom et $a l^{18}$ and Son et $a l^{19}$ concluded that the higher costs were largely due to the more expensive consumables. Our results showed that the cost was mainly concentrated in the range from $¥ 50000$ to $¥ 100000$. The cost of material accounted for the highest composition (52.19\%), followed by drug cost $(30.75 \%)$. Considering the per hospitalised cost with rectal cancer, we concluded that the cost of material is higher than the other ${ }^{20}$ for the following reasons: First, compared with other treatments, the demand for medical materials is typically larger in the surgical procedure. ${ }^{12}$ Second, with the extensive replacement of new and delicate medical materials, the corresponding price is on the rise. ${ }^{21}$ Third, it may be related to the inclusion and exclusion criteria of this study. Therefore, we can conclude that increasing the cost-consciousness of consumables, ${ }^{22}$ reducing intermediate links in material circulation, strengthening price control and intensifying clinical rational use are all essential ways for medical institutions to reduce the cost of treatment.

Combined cardiovascular disease was a protective factor. Many scholars have discussed the interaction between cardiovascular disease and tumours, in which cardiovascular disease limits the treatment of a tumour and the tumour limits the treatment of cardiovascular disease as well. ${ }^{23-25}$ PUCH is a cancer-focused hospital in which cardiovascular disease is not our specialised field. There were reports ${ }^{2324}$ that certain drugs were considered to be conducive to increasing the surgical patient's tolerance compared with these cardiac patients. These explanations could explain why patients with cancer combined with cardiovascular disease had a relatively lower inpatient cost. However, scientifically, the specific mechanism is not yet clear and requires further in-depth study. We found that hypertension and other neoplasms were risk factors for the higher cost. Nasserinejad et al found that hypertension adds the risk of mortality in patients with CRC. ${ }^{26}$ It is widely confirmed that hypertension is an important health issue and is likely to have an impact on expenditure. ${ }^{27}{ }^{28}$ For other tumours, multivisceral resection is gradually applied, ${ }^{29}$ increasing medical expenses directly. Regarding diabetes, we did not find a statistically significant expenditure difference. Although diabetes mellitus was referred to as a possible determinant for progression-free survival in localised CRC, ${ }^{30}$ there is no robust evidence between CRC adverse impact and pre-existing diabetes. ${ }^{31}$

Standardised clinical pathway and real-time settlement could both reduce overall hospitalisation costs, which were consistent with other researchers. ${ }^{32} 33$ Studies have shown that the clinical pathway can effectively contribute to the reduction of the LOS, ${ }^{34-36}$ eventually leading to less direct medical expense. Sylvester and George conducted an integrative review and found that the asthma care pathway for patient with asthma could reduce the hospitalisation cost. ${ }^{35}$ Ellis et al also demonstrated that the clinical pathway is a tool for assisting oncology practice in decreasing costs. ${ }^{32}$ The previous study showed that insurance benefit design could control care utilisation 
Table 3 Inpatient cost categories and univariate analysis

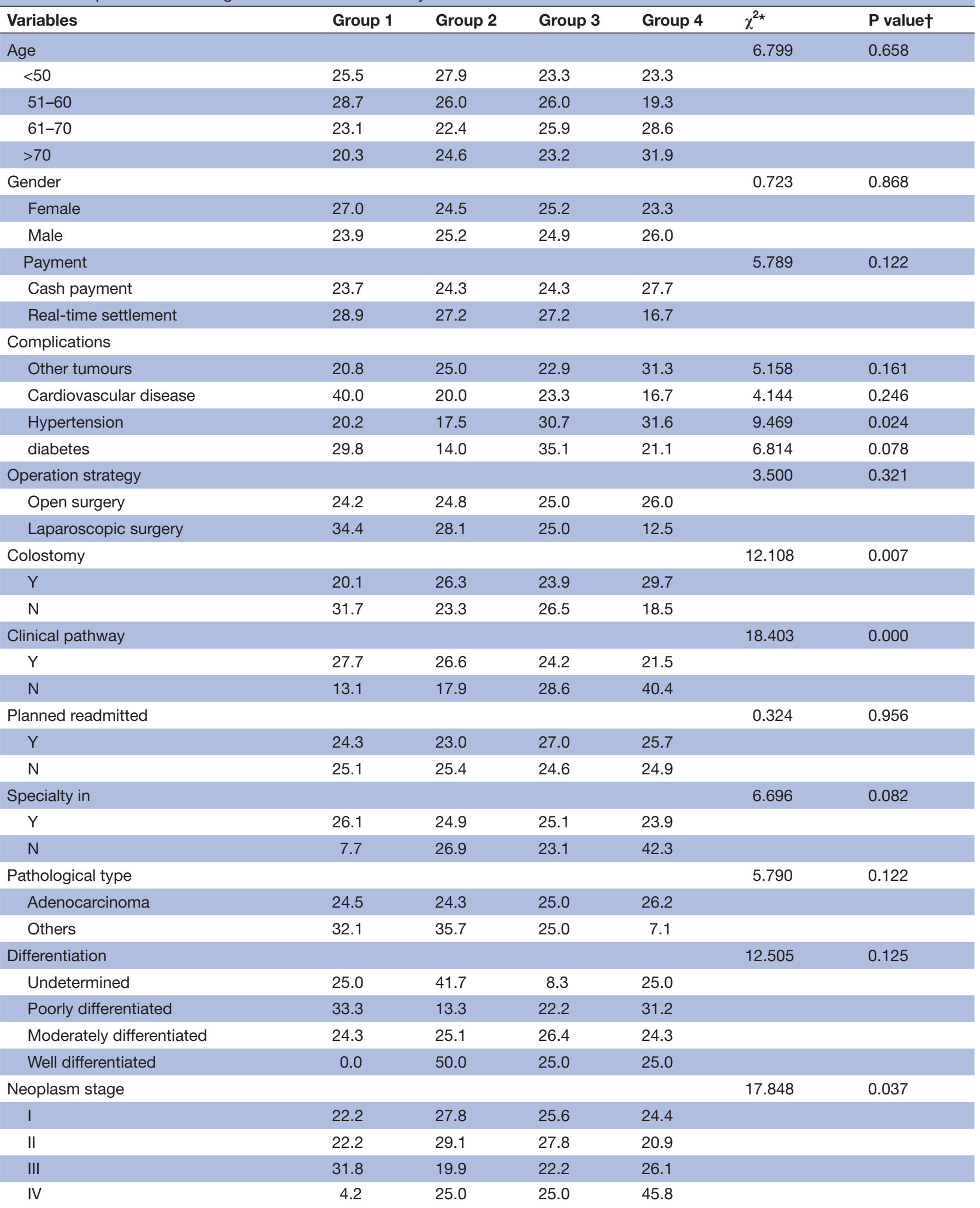

*All parameters were appropriately compared by $\chi^{2}$ test with two-sided verification.

†Only hypertension complications, neoplasm stage and applied colostomy and clinical pathway were not found to have statistical differences under 0.05 power. 


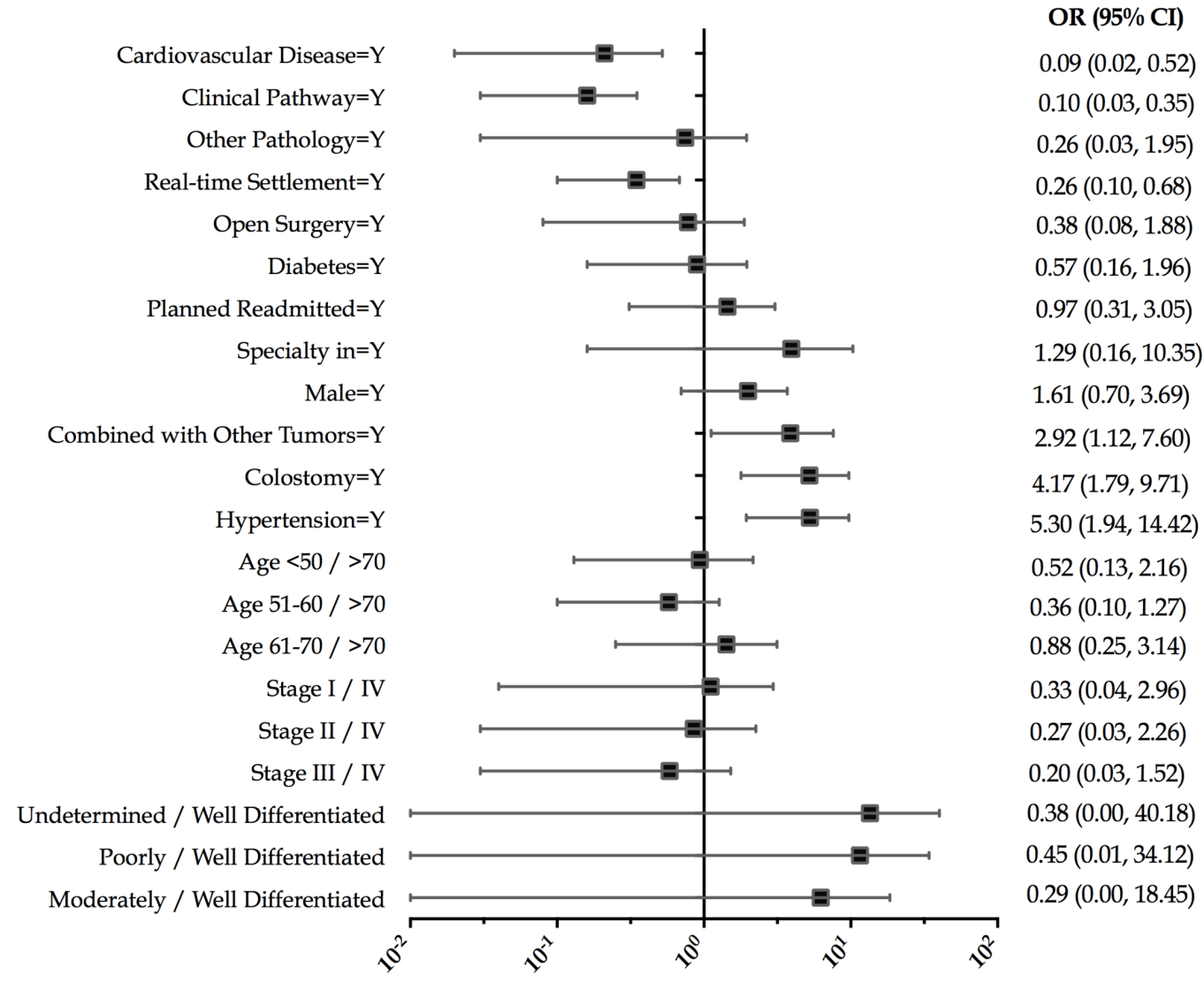

Figure 3 Multivariate analysis of inpatient cost. Statistical risks of relevant variables were displayed by the forest plot right side. In addition, variables on the left of the cutting line represented the protective factors and on the right represented the risk factors correspondingly.

and save cost. $^{37}$ Official medical insurance agencies could supervise the patients' hospital costs online, and bills will not be paid if medical behaviours ran counter to the insurance policy, such as faked declaration, drug quantity exceeds reimbursement coverage in one single visit and indiscriminate charge. Thus, it can play a regulatory role in controlling healthcare expenditure. In addition, the implementation of medical insurance could be of benefit to the control of medical expense depending on the joint effort among patient, hospital and government. $^{33} 38$ Almost three-quarters of patients were in the cash payment group, and the expenditure of those patients was relatively high, which interestingly suggests a feasible direction for the future reform of health insurance policies.

The colostomy was a risk factor for higher cost undoubtedly. Colostomy is an involute procedure, and the separation of adhesion between the abdominal wall and bowel is also complicated ${ }^{39}$ and consumes more surgical time. Due to occasional excess bleeding control, ${ }^{40}$ the medical consumables will be increased, as well as the labour service of doctors and nurses.

In conclusion, this study showed that colostomy, realtime settlement, clinical pathway and comorbidities are all independent factors that affect the hospitalisation cost of LAR surgical patients with rectal cancer. To alleviate the economic burden of patients with cancer, it suggests that rationally promoting the clinical pathway, optimising the payment scheme and controlling the complication are effective approaches. Additionally, because of the limitations of the study, further research focused on a full-cost investigation in different stages of rectal cancer based on a longitudinal design is needed.

\section{Consent to participate}

Anonymised and de-identified data, as well as no interventions, were used, so informed consent was waived.

\section{Author affiliations}

${ }^{1}$ Department of Medical Insurance, Peking University Cancer Hospital and Institute, Key Laboratory of Carcinogenesis and Translational Research (Ministry of Education), Beijing, China

${ }^{2}$ Department of GI Cancer Center Surgery Unit III, Peking University Cancer Hospital and Institute, Key Laboratory of Carcinogenesis and Translational Research (Ministry of Education), Beijing, China

${ }^{3}$ Institute of Health Management and Education, Capital Medical University, Beijing, China

${ }^{4}$ Department of GI Cancer Center Surgery Unit I, Peking University Cancer Hospital and Institute, Key Laboratory of Carcinogenesis and Translational Research (Ministry of Education), Beijing, China

Acknowledgements We thank all of the participants of this study.

Contributors JL and GG conceptualised and designed this study. ZC and LZ managed the fieldwork and data collection. YY and ZC participated in the data analysis and statistical analysis. ZC wrote the first draft. All authors made a contribution to the revision of the manuscript. All authors read and approved the final version of the manuscript. 
Funding The authors have not declared a specific grant for this research from any funding agency in the public, commercial or not-for-profit sectors.

Competing interests None declared.

Patient consent for publication Not required.

Ethics approval The research was examined and certified by the Ethics Committee of Beijing Cancer Hospital.

Provenance and peer review Not commissioned; externally peer reviewed.

Data sharing statement The datasets are available from the corresponding author on reasonable request.

Open access This is an open access article distributed in accordance with the Creative Commons Attribution Non Commercial (CC BY-NC 4.0) license, which permits others to distribute, remix, adapt, build upon this work non-commercially, and license their derivative works on different terms, provided the original work is properly cited, appropriate credit is given, any changes made indicated, and the use is non-commercial. See: http://creativecommons.org/licenses/by-nc/4.0/.

\section{REFERENCES}

1. Binefa G, Rodríguez-Moranta F, Teule A, et al. Colorectal cancer: from prevention to personalized medicine. World J Gastroenterol 2014;20:6786-808.

2. Lan L, Cai Y, Zhang T, et al. Influencing factors of inpatient expenditure pattern for cancer in China, 2015. Chin J Cancer Res 2017;29:11-17

3. Chen W, Zheng R, Zhang S, et al. Cancer incidence and mortality in China in 2013: an analysis based on urbanization level. Chin $J$ Cancer Res 2017;29:1-10.

4. Chen W, Zheng R, Baade PD, et al. Cancer statistics in China, 2015. CA Cancer J Clin 2016;66:115-32.

5. Gu J, Chen N. Current status of rectal cancer treatment in China. Colorectal Dis 2013;15:1345-50.

6. Gao F, Xu M, Song F, et al. Prevention of anastomotic fistula formation after low-position Dixon Operation. Pak J Med Sci 2014:30:1007-10.

7. Gietelink L, Wouters M, Marijnen CAM, et al. Changes in nationwide use of preoperative radiotherapy for rectal cancer after revision of the national colorectal cancer guideline. Eur J Surg Oncol 2017;43:1297-303.

8. Yu DS, Huang XE, Zhou JN. Comparative study on the value of anal preserving surgery for aged people with low rectal carcinoma in Jiangsu, China. Asian Pac J Cancer Prev 2012;13:2339-40.

9. Mathis KL, Pemberton JH. New developments in colorectal surgery. Curr Opin Gastroenterol 2015;31:62-8

10. Chen $X L$, Chen ZQ, Zhu SL, et al. Prognostic value of transforming growth factor-beta in patients with colorectal cancer who undergo surgery: a meta-analysis. BMC Cancer 2017;17:240.

11. Kazama K, Aoyama T, Hayashi T, et al. Evaluation of short-term outcomes of laparoscopic-assisted surgery for colorectal cancer in elderly patients aged over 75 years old: a multi-institutional study (YSURG1401). BMC Surg 2017;17:29.

12. Slankamenac K, Slankamenac M, Schlegel A, et al. Impact of postoperative complications on readmission and long-term survival in patients following surgery for colorectal cancer. Int $\mathrm{J}$ Colorectal Dis 2017;32:805-11.

13. Pucciarelli S, Zorzi M, Gennaro N, et al. In-hospital mortality, 30-day readmission, and length of hospital stay after surgery for primary colorectal cancer: A national population-based study. Eur J Surg Oncol 2017:43:1312-23.

14. Fountzilas $\mathrm{C}$, Chang K, Hernandez B, et al. Clinical characteristics and treatment outcomes of patients with colorectal cancer who develop brain metastasis: a single institution experience. $J$ Gastrointest Oncol 2017;8:55-63.

15. Hagman $\mathrm{H}$, Bendahl $\mathrm{PO}$, Melander $\mathrm{O}$, et al. Vasoactive peptides associate with treatment outcome ofbevacizumab-containing therapy in metastatic colorectal cancer. Acta Oncol 2017;56:653-60.

16. Pulte $D$, Jansen $L$, Brenner $H$. Social disparities in survival after diagnosis with colorectal cancer: Contribution of race and insurance status. Cancer Epidemiol 2017;48:41-7.

17. Zhang $\mathrm{F}$, Zhang $\mathrm{Y}$, Zhao W, et al. Metabolomics for biomarker discovery in the diagnosis, prognosis, survival and recurrence of colorectal cancer: a systematic review. Oncotarget 2017;8:35460-72.
18. Mohd-Dom T, Ayob R, Mohd-Nur A, et al. Cost analysis of periodontitis management in public sector specialist dental clinics. BMC Oral Health 2014;14:56.

19. Son HJ, Lee HY, Park JW, et al. Cost-comparison of laparoscopic and open surgery for mid or low rectal cancer after preoperative chemoradiotherapy: data from a randomized controlled trial. World $\mathrm{J}$ Surg 2013;37:214-9.

20. Tan SS, Bakker J, Hoogendoorn ME, et al. Direct cost analysis of intensive care unit stay in four European countries: applying a standardized costing methodology. Value Health 2012;15:81-6.

21. Sivesgaard K, Jöhnk ML, Larsen LP, et al. Comparison of four MRI protocols for detection of extrahepatic colorectal cancer metastases. $J$ Magn Reson Imaging 2017;46:1619-30.

22. Parnes JA, Yeh DH, Glicksman JT, et al. Surgeon-estimated costs of common consumables in otolaryngology. Laryngoscope 2015;125:2690-4.

23. Poldermans D, Bax JJ, Boersma E, et al. Guidelines for pre-operative cardiac risk assessment and perioperative cardiac management in non-cardiac surgery. Eur Heart $J$ 2009;30:2769-812.

24. Poldermans D. Statins and noncardiac surgery: current evidence and practical considerations. Cleve Clin J Med 2009;76 Suppl 4(Suppl 4):S79-S83.

25. Pathak R, Karmacharya P, Aryal MR, et al. Weekend versus weekday mortality in myocardial infarction in the United States: data from healthcare cost and utilization project nationwide inpatient sample. Int J Cardiol 2014;174:877-8.

26. Nasserinejad M, Baghestani AR, Shojaee S, et al. Diabetes mellitus and hypertension increase the risk of colorectal cancer mortality; a robust Bayesian adjustment analysis. Gastroenterol Hepatol Bed Bench 2017;10(Suppl1):S44.

27. Nakamura K, Okamura T, Miura K, et al. Hypertension and medical expenditure in the Japanese population: review of prospective studies. World J Cardiol 2014;6:531-8.

28. Kirkland EB, Heincelman M, Bishu KG, et al. Trends in healthcare expenditures among us adults with hypertension: National estimates, 2003-2014. J Am Heart Assoc 2018;7.

29. Hand F, Sanabria Mateos R, Durand M, et al. Multivisceral resection for locally invasive colorectal liver metastases: Outcomes of a matched cohort analysis. Dig Surg 2018;35:514-9.

30. Croft B, Reed M, Patrick C, et al. Diabetes, obesity, and the metabolic syndrome as prognostic factors in stages i to iii colorectal cancer patients. J Gastrointest Cancer 2018 (Published Online First: 18 Jan 2018).

31. Griffiths RI, Valderas JM, McFadden EC, et al. Outcomes of preexisting diabetes mellitus in breast, colorectal, and prostate cancer. J Cancer Surviv 2017;11:604-13.

32. Ellis PG, O'Neil BH, Earle MF, et al. Clinical pathways: Management of quality and cost in oncology networks in the metastatic colorectal cancer setting. J Oncol Pract 2017;13:e522-e529.

33. Duquette $\mathrm{S}$, Soleimani T, Hartman B, et al. Does payer type influence pediatric burn outcomes? A national study using the healthcare cost and utilization project kids' inpatient database. J Burn Care Res 2016;37:314-20.

34. Cheah J. Clinical pathways-an evaluation of its impact on the quality of care in an acute care general hospital in Singapore. Singapore Med J 2000;41:335-46.

35. Sylvester AM, George M. Effect of a clinical pathway on length of stay and cost of pediatric inpatient asthma admissions: an integrative review. Clin Nurs Res 2014;23:384-401.

36. Walter FL, Bass N, Bock G, et al. Success of clinical pathways for total joint arthroplasty in a community hospital. Clin Orthop Relat Res 2007:457:133-7.

37. Xin $\mathrm{H}$. How do high cost-sharing policies for physician care affect inpatient care use and costs among people with chronic disease? J Ambul Care Manage 2015;38:100-8.

38. Maeda JL, Raetzman SO, Friedman BS. What hospital inpatient services contributed the most to the 2001-2006 growth in the cost per case? Health Serv Res 2012;47:1814-35.

39. Maroney S, Chavez de Paz C, Duldulao M, et al. Complications of diverting ileostomy after low anterior resection for rectal carcinoma. Am Surg 2016;82:1033-7.

40. Jang HW, Kim YN, Nam CM, et al. Factors affecting colonoscope insertion time in patients with or without a colostomy after left-sided colorectal resection. Dig Dis Sci 2012;57:3219-25. 